\title{
Congenital laryngeal palsy
}

INSERM

\section{Source}

INSERM. (1999). Orphanet: an online rare disease and orphan drug data base. Congenital laryngeal palsy. ORPHA:137932

Cong enital laryngeal palsy is a rare larynx anomaly characterized by unilateral or bilateral paralysis of the vocal cords as a result of dysfunction of the motor nerve supply to the larynx. Patients typically present at birth (or shortly thereafter) with stridor, weak or breathy cry, dysphonia or aphonia, feeding or aspiration difficulties and, occasionally, respiratory compromise. Neurological disease, masses that cause compression and aberrant vessels are often associated. Most cases resolve spontaneously over 6-12 months. 